University of Wollongong

Research Online

Faculty of Engineering - Papers (Archive)

Faculty of Engineering and Information

Sciences

2009

\title{
Influence of heat treatment on superconductivity of MgB2 bulk sintered in flowing welding grade ar atmosphere
}

\author{
Yun Zhang \\ University of Wollongong, yunz@uow.edu.au \\ Cheng Lu \\ University of Wollongong, chenglu@uow.edu.au \\ Sihai Zhou \\ University of Wollongong, sihai@uow.edu.au \\ K. C. Chung \\ Korea Institute of Materials Science, South Korea \\ Y. K. Kim \\ Korea Institute of Materials Science, South Korea
}

See next page for additional authors

Follow this and additional works at: https://ro.uow.edu.au/engpapers

Part of the Engineering Commons

https://ro.uow.edu.au/engpapers/3680

\section{Recommended Citation}

Zhang, Yun; Lu, Cheng; Zhou, Sihai; Chung, K. C.; Kim, Y. K.; and Dou, S. X.: Influence of heat treatment on superconductivity of MgB2 bulk sintered in flowing welding grade ar atmosphere 2009, 2626-2629.

https://ro.uow.edu.au/engpapers/3680

Research Online is the open access institutional repository for the University of Wollongong. For further information contact the UOW Library: research-pubs@uow.edu.au 


\section{Authors}

Yun Zhang, Cheng Lu, Sihai Zhou, K. C. Chung, Y. K. Kim, and S. X. Dou 


\title{
Influence of Heat Treatment on Superconductivity of $\mathbf{M g B}_{2}$ Bulk Sintered in Flowing Welding Grade Ar Atmosphere
}

\author{
Y. Zhang ${ }^{1}$, C. Lu $^{2}$, S. H. Zhou ${ }^{1}$, K. C. Chung ${ }^{3}$, Y. K. Kim ${ }^{3}$, and S. X. Dou ${ }^{1}$ \\ ${ }^{1}$ Institute for Superconducting and Electronic Materials, University of Wollongong, Wollongong, NSW 2522, Australia \\ ${ }^{2}$ School of Mechanical, Materials and Mechatronic Engineering, University of Wollongong, Wollongong NSW 2522, Australia \\ ${ }^{3}$ Energy Materials Group, Korea Institute of Materials Science, Changwon, Gyeongnam 641-831, South Korea
}

\begin{abstract}
In this paper, $\mathrm{MgB}_{2}$ samples were sintered in flowing welding grade Ar. The effect of the sintering time varying from 10 minutes to 3 hours on superconductivity of $\mathrm{MgB}_{2}$ has been investigated. It has been found that both $\mathbf{H}_{\mathrm{c} 2}$ and $\mathrm{H}_{\mathrm{irr}}$ increase with the sintering time and they have linear relationships with microstrain. The sample sintered for 30 min exhibits the highest $J_{c}$ at high fields. The reason can be attributed to the improved connectivity and the increased $\mathbf{H}_{\mathrm{c} 2}$.
\end{abstract}

Index Terms $-\mathrm{MgB}_{2}$, microstrain, sintering time, superconductivity.

\section{INTRODUCTION}

$\mathbf{T}$ $\mathrm{HE}$ critical current density $\mathrm{J}_{\mathrm{c}}$ of $\mathrm{MgB}_{2}$ is the most crucial quantity for use in commercial applications. $\mathrm{J}_{\mathrm{c}}$ behavior of $\mathrm{MgB}_{2}$ will be affected by not only processing conditions such as the precursor powders [1]-[6], the heating and cooling rate [7], and the processing temperature and duration [8], as well as the atmosphere [9] but also chemical doping [10]-[13]. Enormous efforts have been made to improve the critical current density, $\mathrm{J}_{\mathrm{c}}$, in $\mathrm{MgB}_{2}$ through chemical doping. Among these doping elements, oxygen represents a special case, as nearly all types of $\mathrm{MgB}_{2}$ materials have been treated in a protected atmosphere such as Ar. Oxygen alloying into $\mathrm{MgB}_{2}$ reduced the critical temperature, $T_{c}$, but improved flux pinning in thin films [14]-[16] and bulks [17]. Recently, Senkowicz et al. have reported the effect of different amounts of exposure time to air during the ball-milling process for pre-reacted $\mathrm{MgB}_{2}$ powder, which was used to prepare $\mathrm{MgB}_{2}$ bulk or wires by the ex situ method [18]. In this case, the effect of atmosphere is limited to the commercially available pre-reacted $\mathrm{MgB}_{2}$. Currently, our group studies demonstrated that the processing atmosphere would have a more significant effect on the superconducting properties in the in situ processed samples, as reactive components in the atmosphere can easily participate in the $\mathrm{MgB}_{2}$ formation process from a mixture of $\mathrm{Mg}$ and $\mathrm{B}$ powders. The $\mathrm{J}_{\mathrm{c}}, \mathrm{H}_{\mathrm{irr}}$ and $\mathrm{H}_{\mathrm{c} 2}$ for the welding grade Ar processed sample are improved in comparison with the samples treated in ultra-high and high purity argon [19]. In addition, Oxygen is incorporated in bulk $\mathrm{MgB}_{2}$ in various forms such as nanometer-sized $\mathrm{MgB}_{2-\mathrm{x}} \mathrm{O}_{\mathrm{x}}$ precipitates in the grains and $\mathrm{MgO}$ particles in the interior of the grains due to different annealing time and cooling rate [17], [20], [21]. In order to result in an optimal doping effect, we report here the effect of annealing time on the critical temperature $T_{c}$, resistivity, connectivity, the upper critical field $\mathrm{H}_{\mathrm{c} 2}$ and the critical current density $\mathrm{J}_{\mathrm{C}}$ of $\mathrm{MgB}_{2}$ bulk when sintered in flowing welding grade Ar atmosphere.

Manuscript received October 16, 2008. Current version published May 20, 2009. Corresponding author: Y. Zhang (e-mail: yz268@uow.edu.au).

Color versions of one or more of the figures in this paper are available online at http://ieeexplore.iee.org.

Digital Object Identifier 10.1109/TMAG.2009.2018924

\section{EXPERIMENTAL DETAILS}

$\mathrm{MgB}_{2}$ pellet samples were prepared by in situ reaction method which has been previously described in detail [10]. Powders of magnesium (99\%) and amorphous boron (99\%) with the stoichiometry of $\mathrm{MgB}_{2}$ were well mixed. The mixed powder was pressed under a pressure of 5 tons in a hydraulic press, packed into a Fe tube without sealing, heated to $700^{\circ} \mathrm{C}$, and then held for 10 minutes, 30 minutes, and 3 hours in flowing welding grade $\operatorname{Ar}(99.995 \%)$. The samples sintered for $10 \mathrm{~min}, 30 \mathrm{~min}$ and $3 \mathrm{~h}$ are termed as samples A, B, and $\mathrm{C}$, respectively, in the following context. The reason for the use of the processing parameters of $700^{\circ} \mathrm{C}$ is because these are optimal conditions to achieve the best $\mathrm{J}_{\mathrm{c}}(\mathrm{H})$ performance, based on our previous study [8]. Although heat treatment at $900^{\circ} \mathrm{C}$ or higher can achieve optimal $\mathrm{T}_{c}$ [8], [22]-[24], this does not provide optimal conditions for $\mathrm{J}_{\mathrm{c}}(\mathrm{H})$ performance [8]. The Fe tubes were only used as sample holders. They had a diameter of $12 \mathrm{~mm}$ and a length of $20 \mathrm{~mm}$, with the two ends open so that Ar could freely flow through the samples. The sintering was followed by furnace cooling to room temperature. Phase analysis was carried out by X-ray diffraction (XRD) in a Philips PW1730 Model diffractometer using $\mathrm{Cu} \mathrm{K} \alpha$ radiation. Magnetic measurements of the samples were conducted in a commercial Quantum Design Physical Properties Measurement System (PPMS) after they had been polished into a cuboid shape for measurements. Their dimensions were accurately measured with a digital micrometer. The DC magnetic response was obtained in an applied low field of 1 Oe using the conventional zero-field-cooled (ZFC) and field-cooled (FC) procedures. The resistivity as a function of temperature and magnetic field was measured using a four-probe measurement technique.

\section{RESUlTS AND DISCUSSION}

The XRD patterns for $\mathrm{MgB}_{2}$ samples processed under different annealing times are shown in Fig. 1. As can be seen, all samples show high-purity $\mathrm{MgB}_{2}$ phase with $\mathrm{MgO}$ as a minor impurity phase. There is a small amount of $\mathrm{MgB}_{4}$ in sample $\mathrm{A}$. The Rietveld refinement method was performed to analyse the XRD measurements. The refined parameters include the weight 


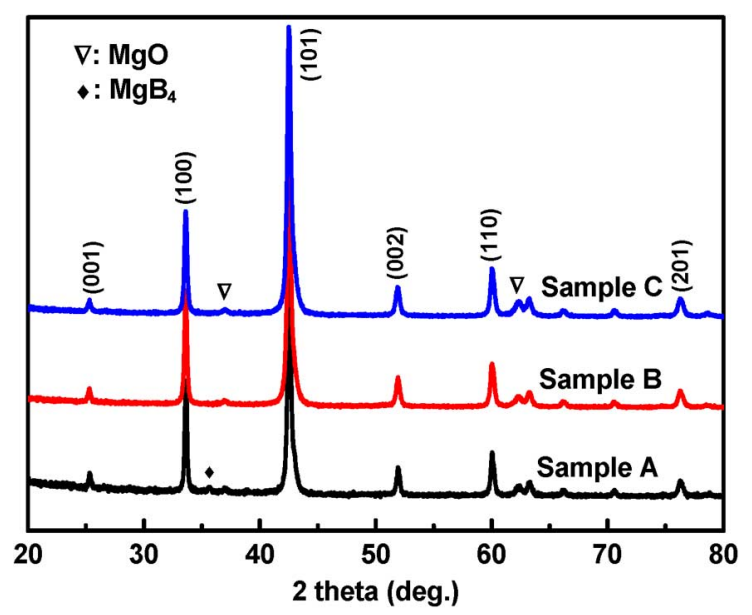

Fig. 1. Powder XRD patterns of $\mathrm{MgB}_{2}$ samples.

TABLE I

PARAMETERS FOR THE THREE SAMPLES

\begin{tabular}{|c|c|c|c|c|c|}
\hline \multirow{2}{*}{ Samples } & \multirow{2}{*}{$\begin{array}{l}\text { Sintering } \\
\text { time }\end{array}$} & \multirow{2}{*}{$\begin{array}{c}\mathrm{MgO} \\
(\%)\end{array}$} & \multirow{2}{*}{$\begin{array}{c}\mathrm{MgB}_{4} \\
(\%)\end{array}$} & \multicolumn{2}{|c|}{ Lattice parameters } \\
\hline & & & & $\mathrm{a}(\AA)$ & $\mathrm{a}(\AA)$ \\
\hline $\mathrm{A}$ & $10 \mathrm{~min}$ & 4.75 & 5.82 & 3.083 & 3.524 \\
\hline $\mathrm{B}$ & $30 \mathrm{~min}$ & 6.44 & & 3.082 & 3.522 \\
\hline $\mathrm{C}$ & $3 \mathrm{~h}$ & 8.5 & & 3.085 & 3.526 \\
\hline Samples & $\begin{array}{c}\text { Microstrains } \\
(\%)\end{array}$ & $\begin{array}{l}\mathrm{T}_{\mathrm{c}} \\
(\mathrm{K})\end{array}$ & $\begin{array}{c}\rho_{300 \mathrm{~K}} \\
(\mu \Omega \mathrm{cm})\end{array}$ & $\begin{array}{c}\rho_{40 \mathrm{~K}} \\
(\mu \Omega \mathrm{cm})\end{array}$ & $\mathrm{A}_{\mathrm{F}}$ \\
\hline $\mathrm{A}$ & 0.348 & 37.48 & 97.55 & 41.99 & 0.13 \\
\hline $\mathrm{B}$ & 0.426 & 37.09 & 72.16 & 37.45 & 0.21 \\
\hline $\mathrm{C}$ & 0.456 & 37.24 & 122.67 & 73.59 & 0.15 \\
\hline
\end{tabular}

fraction of each phase, the lattice parameters of $\mathrm{MgB}_{2}$ and the microstrain. They are shown in Table I.

From Table I it can be seen that as the sintering time increases from $10 \mathrm{~min}$ to $30 \mathrm{~min}$, lattice parameters $a$ and $c$ decreases. Lattice parameter $a$ of sample B has been reduced below the ideal value $(a=3.083 \AA)$. This indicates that oxygen atoms have diffused into the $\mathrm{MgB}_{2}$ lattice. They may squeeze into the lattice as the interstitial atoms or replace the boron atoms to form $\mathrm{MgB}_{2-\mathrm{x}} \mathrm{O}_{\mathrm{x}}$ precipitates [21], leading to the reduced lattice parameters. Since the diffusion density of the oxygen atom increases with the sintering time, the lattice parameters decreases from sample A to sample B. However, when the sintering time is further increased, the diffused oxygen atoms saturate and part of them react with $\mathrm{Mg}$ atoms to form $\mathrm{MgO}$ for long sintering time ( 3 hours in sample C). Table I has shown that the fraction of $\mathrm{MgO}$ increases when the sintering time increases from $30 \mathrm{~min}$ to 3 hours. The reaction of the diffused oxygen atoms and $\mathrm{Mg}$ atoms reduces the interstitial oxygen atoms and induce the $\mathrm{Mg}$ deficiency, both of which result in the increased lattice parameters in sample $\mathrm{C}$ as shown in Table I.

$\mathrm{T}_{\mathrm{c}} \mathrm{s}$ are listed in Table I. Sample B has a smallest value. $\mathrm{T}_{\mathrm{c}}$ varies within a small range of $0.5 \mathrm{~K}$. This indicates that the sintering time does not significantly affect $T_{c}$. Fig. 2 shows the resistivity-temperature curves for the three samples. The resistivity $(\rho)$ for sample $\mathrm{C}$ is the largest among samples. The values of $\rho_{40 \mathrm{~K}}$ and $\rho_{300 \mathrm{~K}}$ are collected from Fig. 2 and listed in Table I. Sample B exhibits the smallest $\rho_{40 \mathrm{~K}}$ and $\rho_{300 \mathrm{~K}}$,

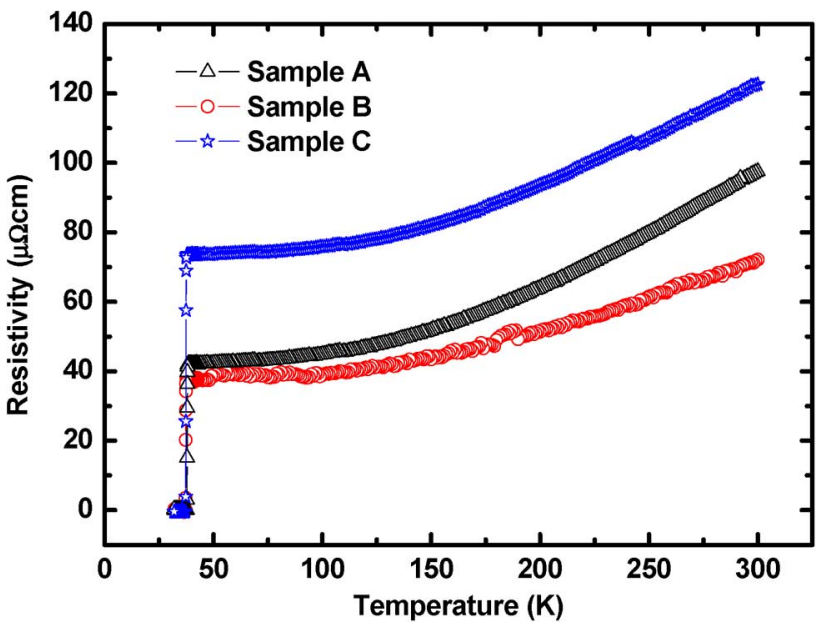

Fig. 2. Resistivity versus temperature.

whereas sample $\mathrm{C}$ has the largest value. The values for $\rho_{40 \mathrm{~K}}$ listed in Table I are higher than the single crystal $(5.3 \mu \Omega \mathrm{cm}$, [25]) and the dense filament made by chemical vapor deposition (CVD) $(7.3 \mu \Omega \mathrm{cm},[26])$. The reason can be attributed to poor connectivity in the studied samples. The XRD patterns in Fig. 1 show the existence of $\mathrm{MgO}$ in the samples. $\mathrm{MgO}$ is mainly present in the grain boundary as an insulating phase, which reduces the effective cross-sectional area of the samples and then increases the resistivity. The effective cross-sectional area $\left(\mathrm{A}_{\mathrm{F}}\right)$ can be estimated by the equation, $\mathrm{A}_{\mathrm{F}}=\Delta \rho_{\text {ideal }} /\left(\rho_{300 \mathrm{~K}}-\right.$ $\left.\rho_{40 \mathrm{~K}}\right)$, which was proposed by Rowell [22]. $\Delta \rho_{\text {ideal }}$ is the ideal change in resistivity from $300 \mathrm{~K}$ to $40 \mathrm{~K}$ for a fully connected sample. It is set to be $7.3 \mu \Omega \mathrm{cm}$ according to [27]. The calculated $A_{F}$ is displayed in Table I. It can be found that all samples have low $A_{F} s$, indicating poor connection in the samples.

Sample B has larger $A_{F}$ than sample A. This may be due to the improved crystallinity and disappearance of $\mathrm{MgB}_{4}$ with increased sintering time. However, $A_{F}$ in sample $C$ is smaller than sample B. The reason can be attributed to larger amount of $\mathrm{MgO}$ in sample $\mathrm{C}$, which obstructs the flow of the current and increases the resistivity.

From the resistivity curves under different magnetic fields, the irreversibility field $\left(\mathrm{H}_{\mathrm{irr}}\right)$ and the upper critical field $\left(\mathrm{H}_{\mathrm{c} 2}\right)$, can be derived, using the $10 \%$ and $90 \%$ of the normal state resistivity. The results are shown in Fig. 3. It can be seen that $\mathrm{H}_{\mathrm{c} 2}$ has the concave temperature-dependence curves. It is evident that $\mathrm{H}_{\mathrm{c} 2}$ and $\mathrm{H}_{\text {irr }}$ in the limited field regime measured increase with the sintering time. $\mathrm{H}_{\mathrm{c} 2} \mathrm{~s}$ and $\mathrm{H}_{\mathrm{irr}} \mathrm{s}$ at $\mathrm{T} / \mathrm{T}_{\mathrm{c}}=0.7$ for the three samples have been collected from Fig. 3 and plotted against microstrain in the inset of Fig. 3. It is clear that both $\mathrm{H}_{\mathrm{c} 2}$ and $\mathrm{H}_{\mathrm{irr}}$ linearly increase with microstrain. The low microstrain indicates less lattice distortion inside the $\mathrm{MgB}_{2}$ grains and then larger mean free path $(l)$ of the superconducting electrons. This will increase the coherence length $(\xi)$ due to the relation: $1 / \xi=1 / \xi_{0}+1 / l$, where $\xi_{0}$ is the value of $\xi$ for the pure superconductor. According to $\mathrm{H}_{\mathrm{c} 2}=\Phi_{0} /\left(2 \pi \mu_{0} \xi^{2}\right)$, where $\Phi_{0}$ is the superconducting flux quantum and $\mu_{0}$ is the magnetic permeability, $\mathrm{H}_{\mathrm{c} 2}$ will decrease as $\xi$ increases.

Fig. 4 shows the $\mathrm{J}_{\mathrm{c}}(\mathrm{H})$ curves for the three samples at $5 \mathrm{~K}$ and $20 \mathrm{~K}$. It can be seen that the $\mathrm{J}_{\mathrm{c}}$ performance in sample $\mathrm{B}$ shows a 


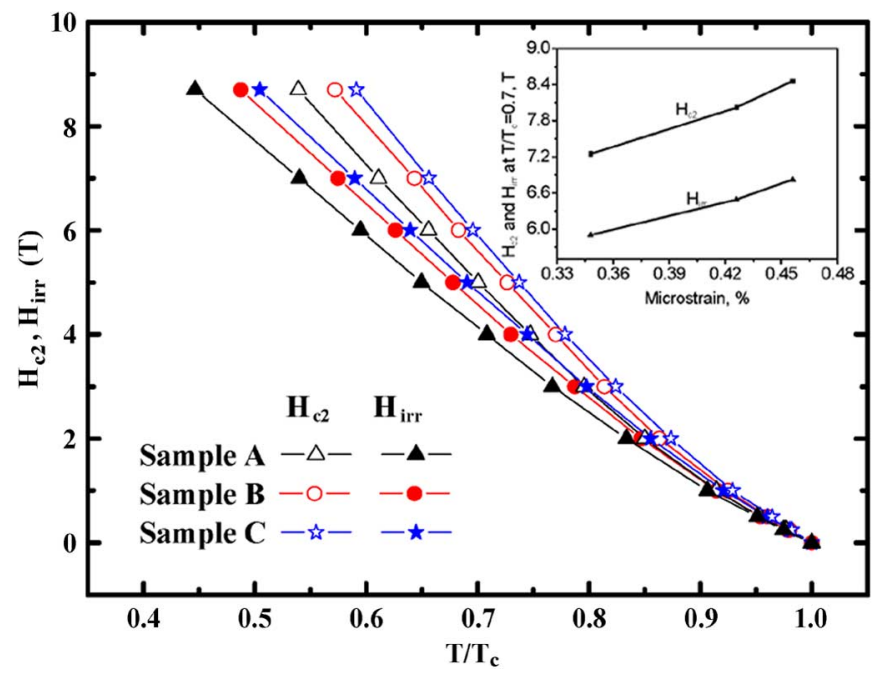

Fig. 3. Temperature dependence of $\mathrm{H}_{\mathrm{c} 2}$ and $\mathrm{H}_{\mathrm{irr}}$.

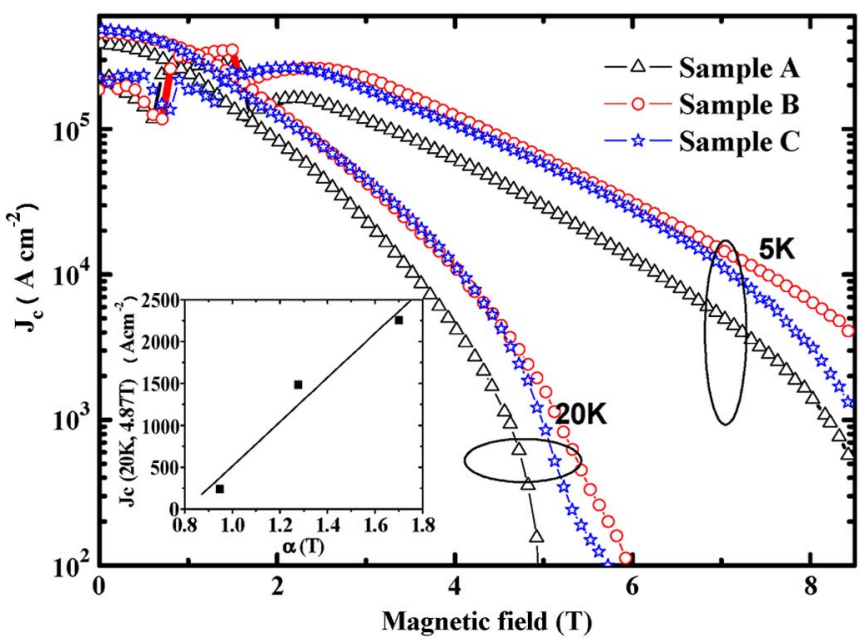

Fig. 4. $\mathrm{J}_{\mathrm{c}}(\mathrm{H})$ curves at $5 \mathrm{~K}$ and $20 \mathrm{~K}$ for $\mathrm{MgB}_{2}$ samples. The inset shows $\mathrm{J}_{\mathrm{c}}$ at $20 \mathrm{~K}$ and $4.87 \mathrm{~T}$ as a function of $\alpha=\mathrm{A}_{\mathrm{F}} \cdot \mathrm{H}_{\mathrm{C} 2}$ for the three samples.

significant improvement under high fields at both $5 \mathrm{~K}$ and $20 \mathrm{~K}$. Sample B exhibits the highest $\mathrm{J}_{\mathrm{c}}$ of $\sim 6722 \mathrm{Acm}^{-2}$ at $5 \mathrm{~K}$ and $8 \mathrm{~T}$, which is more than five times higher than that of sample A and almost 2 times higher than that of sample $\mathrm{C}$. The $\mathrm{J}_{\mathrm{C}}$ values at $20 \mathrm{~K}$ and $4.87 \mathrm{~T}$ follow the same trend, namely $360 \mathrm{Acm}^{-2}$, $2450 \mathrm{Acm}^{-2}$ and $1840 \mathrm{Acm}^{-2}$ for sample A, B and C, respectively. It has been known that the grain boundary pinning is the major pinning mechanism at high fields in $\mathrm{MgB}_{2}$. The $\mathrm{J}_{\mathrm{c}}$ caused by the surface pinning can be calculated by $\mu_{0} \mathrm{~S}_{\mathrm{v}}\left(\mathrm{H}_{\mathrm{c} 2}-\right.$ $\mathrm{H})^{2} / 4 \kappa^{2} \mathrm{H}_{\mathrm{c} 2}^{1 / 2} \mathrm{H}^{1 / 2}$ [28], where $\mathrm{S}_{\mathrm{v}}$ is the grain boundary surface area per unit volume, $\mathrm{H}_{\mathrm{c} 2}$ is the upper critical field, $\kappa$ is the Ginzburg-Landau parameter and $\mathrm{H}$ is the applied field. It can be concluded from this equation that $\mathrm{J}_{\mathrm{c}}$ at high fields near $\mathrm{H}_{\mathrm{c} 2}$ is dominantly determined by $\mathrm{H}_{\mathrm{c} 2}$ and $\mathrm{S}_{\mathrm{v}}$ [29]. In addition, the connectivity $\left(A_{F}\right)$ also affects $J_{c}$. Fig. 5 shows field emission gun scanning electron microscope (FEG-SEM) images of samples A, B and C. It can be seen that the grain size has no significant change among samples. Therefore, the $\mathrm{J}_{\mathrm{c}}$ difference is not caused by the change of $\mathrm{S}_{\mathrm{v}}$. We calculate a parameter $\alpha=\mathrm{A}_{\mathrm{F}} \mathrm{H}_{\mathrm{c} 2}$, which combines two major factors $\left(\mathrm{A}_{\mathrm{F}}\right.$ and $\left.\mathrm{H}_{\mathrm{c} 2}\right)$ influencing $\mathrm{J}_{\mathrm{C}}$ and plot $\alpha$ against $\mathrm{J}_{\mathrm{C}} \mathrm{s}$ at $20 \mathrm{~K}$ and $4.87 \mathrm{~T}$ for

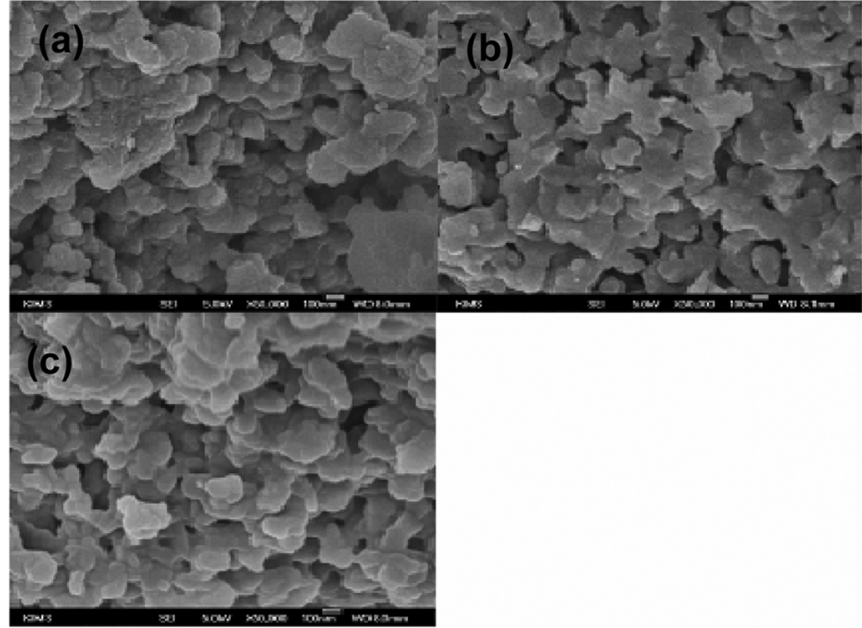

Fig. 5. FEG-SEM images for (a) sample A, (b) sample B and (c) sample C.

three samples in the inset of Fig. 4. Fig. 3 could not give the $\mathrm{H}_{\mathrm{c} 2}$ values at $20 \mathrm{~K} . \mathrm{H}_{\mathrm{c} 2}$ at $22.5 \mathrm{~K}$ is roughly used to replace $\mathrm{H}_{\mathrm{c} 2}$ at $20 \mathrm{~K}$. This figure produces a very good linear relationship between $\alpha$ and $\mathrm{J}_{\mathrm{c}}$. It clearly indicates that the improved $\mathrm{J}_{\mathrm{c}}$ is mainly caused by the improved connectivity and the increased $\mathrm{H}_{\mathrm{c} 2}$.

\section{CONCLUSION}

$\mathrm{MgB}_{2}$ samples were prepared by in situ reaction method and sintered in flowing welding grade Ar. The effect of the sintering time on superconductivity of $\mathrm{MgB}_{2}$ has been investigated. The sintering time changes by 10 minutes, 30 minutes and 3 hours. It has been found that the amount of $\mathrm{MgO}$ increases with the sintering time and the sample with 30 minutes sintering time has the smallest lattice parameters. $\mathrm{H}_{\mathrm{c} 2}$ and $\mathrm{H}_{\mathrm{irr}}$ increase with the sintering time and they have linear relationships with microstrain. The sample sintered for $30 \mathrm{~min}$ exhibits the highest $\mathrm{J}_{\mathrm{c}}$ at high fields. The reason can be attributed to the improved connectivity and the increased $\mathrm{H}_{\mathrm{c} 2}$.

\section{ACKNOWLEDGMENT}

The author would like to thank Dr. T. Silver for helpful discussions, Dr. J. Horvat for his help with measurements, the Australian Research Council, Hyper Tech Research Inc. and CMS Alphatech International Ltd for financial support.

\section{REFERENCES}

[1] H. Fang, S. Padmanabhan, Y. X. Zhou, and K. Salama, "High critical current density in iron-clad $\mathrm{MgB}_{2}$ tapes," Appl. Phys. Lett., vol. 82, p. 4113, 2003.

[2] A. Matsumoto, H. Kumakura, H. Kitaguchi, H. Hatakeyama, H. Yamada, and M. Hirakawa, "The microstructures and superconducting properties of $\mathrm{MgB}_{2}$ tapes processed in situ by a ball-milling method," IEEE Trans. Appl. Supercond., vol. 15, p. 3333, 2005.

[3] W. Häßler, B. Birajdar, W. Gruner, M. Herrmann, O. Perner, C. Rodig, M. Schubert, B. Holzapfel, O. Eibl, and L. Schultz, " $\mathrm{MgB}_{2}$ bulk and tapes prepared by mechanical alloying: Influence of the boron precursor powder," Supercond. Sci. Technol., vol. 19, p. 512, 2006.

[4] R. A. Ribeiro, S. L. Bud'ko, C. Petrovic, and P. C. Canfield, "Effects of stoichiometry, purity, etching and distilling on resistance of $\mathrm{MgB}_{2}$ pellets and wire segments," Physica C, vol. 382, p. 194, Nov. 2002.

[5] S. K. Chen, K. A. Yates, M. G. Blamire, and J. L. MacManus-Driscoll, "Strong influence of boron precursor powder on the critical current density of $\mathrm{MgB}_{2}$," Supercond. Sci. Technol., vol. 18, p. 1473, 2005. 
[6] Y.Zhang, X. Xu, Y. Zhao, J. H. Kim, C. Lu, S. H. Zhou, and S. X. Dou, "Significant improvement of $\mathrm{J}_{\mathrm{c}}$ in $\mathrm{MgB}_{2}$ bulk superconductor using ball-milled high-purity crystalline boron," Supercond. Sci. Technol., vol. 21, p. 115004, Nov. 2008.

[7] O. V. Shcherbakova, A. V. Pan, S. Soltanian, S. X. Dou, and D. Wexler, "Influence of the cooling rate on the main factors affecting current-carrying ability in pure and $\mathrm{SiC}$-doped $\mathrm{MgB}_{2}$ superconductors," Supercond. Sci. Technol., vol. 20, p. 5, 2007.

[8] J. H. Kim, S. X. Dou, J. L. Wang, D. Q. Shi, X. Xu, M. S. A. Hossain, W. K. Yeoh, S. Choi, and T. Kiyoshi, "The effects of sintering temperature on superconductivity in $\mathrm{MgB}_{2} / \mathrm{Fe}$ wires," Supercond. Sci. Technol., vol. 20, p. 448, Mar. 2007.

[9] K. S. Tan, N.-K. Kim, Y.-J. Kim, B.-H. Jun, and C.-J. Kim, "Influence of heat treatment on the critical current density of $\mathrm{MgB}_{2}$ bulk sintered in vacuum and flowing Ar atmosphere," Physica C, vol. 468, p. 1366, 2008.

[10] S. X. Dou, S. Soltanian, J. Horvat, X. L. Wang, S. H. Zhou, M. Ionescu, H. K. Liu, P. Munroe, and M. Tomsic, "Enhancement of the critical current density and flux pinnin of $\mathrm{MgB}_{2}$ superconductor by nanoparticle SiC doping," Appl. Phys. Lett., vol. 81, p. 3419, 2002.

[11] R. H. T. Wilke, S. L. Bud'ko, P. C. Canfield, D. K. Finnemore, R. J. Suplinskas, and S. T. Hannahs, "Systematic effects of carbon doping on the superconducting properties of $\mathrm{Mg}\left(\mathrm{B}_{1-\mathrm{x}} \mathrm{C}_{\mathrm{x}}\right)_{2}$," Phys. Rev. Lett., vol. 92, p. 217003, May 2004.

[12] H. Kumakura, H. Kitaguchi, A. Matsumoto, and H. Hatakeyama, "Upper critical fields of powder-in-tube-processed $\mathrm{MgB}_{2} / \mathrm{Fe}$ tape conductors," Appl. Phys. Lett., vol. 84, p. 3669, Apr. 2004.

[13] M. D. Sumption, M. Bhatia, M. Rindfleisch, M. Tomsic, S. Soltanian, and S. X. Dou, "Large upper critical field and irreversibility field in $\mathrm{MgB}_{2}$ wires with SiC additions," Appl. Phys. Lett., vol. 86, p. 092507 , Feb. 2005.

[14] N. C. B. Eom, M. K. Lee, and J. H. Choi et al., "High critical current density and enhanced irreversibility field in superconducting $\mathrm{MgB}_{2}$ thin films," Nature, vol. 411, p. 558, May 2001.

[15] K. A. Yates, Z. Lockman, A. Kursumovic, G. Burnell, N. A. Stelmashenkov, J. L. MacManus Driscoll, and M. G. Blamire, "The effect of oxygenation on the superconducting properties of $\mathrm{MgB}_{2}$ thin films," Appl. Phys. Lett., vol. 86, p. 022502, Jan. 2005.

[16] R. K. Singh, Y. Shen, R. Gandikota, J. M. Rowell, and N. Newman, "Effect of stoichiometry on oxygen incorporation in $\mathrm{MgB}_{2}$ thin films," Supercond. Sci. Technol., vol. 21, p. 015018, Jan. 2008.
[17] X. Z. Liao, A. C. Serquis, Y. T. Zhu, J. Y. Huang, D. E. Peterson, F. M. Mueller, and H. F. Xu, "Controlling flux pinning precipitates during $\mathrm{MgB}_{2}$ synthesis,” Appl. Phys. Lett., vol. 80, p. 4398, 2002.

[18] B. J. Senkowicz, R. Pérez Moyet, R. J. Mungall, J. Hedstrom, O. N C. Uwakweh, E. E. Hellstrom, and D. C. Larbalestier, "Atmospheric conditions and their effect on ball-milled magnesium diboride," Supercond. Sci. Technol., vol. 19, p. 1173, Nov. 2006.

[19] S. X. Dou, Y. Zhang, X. Z. Liao, S. H. Zhou, G. Peleckis, A. V. Pan, and X. L. Wang, 2008, Effect of Processing Atmosphere on Critical Current Density of $\mathrm{MgB}_{2}$ submitted for publication, 2008.

[20] R. F. Klie, J. C. Idrobo, N. D. Browing, A. Serquis, Y. T. Zhu, X. Z Liao, and F. M. Mueller, "Observation of coherent oxide precipitates in polycrystalline $\mathrm{MgB}_{2}$," Appl. Phys. Lett., vol. 80, p. 3970, May 2002.

[21] X. Z. Liao, A. Serquis, Y. T. Zhu, J. Y. Huang, L. Civale, D. E. Peterson, F. M. Mueller, and $\mathrm{H}$. F. Xu, " $\mathrm{Mg}(\mathrm{B}, \mathrm{O})_{2}$ precipitation in MgB $_{2}$," J. Appl. Phys., vol. 93, p. 6208, May 2003.

[22] J. M. Rowell, "The widely variable resistivity of $\mathrm{MgB}_{2}$ samples," $\mathrm{Su}$ percond. Sci. Technol., vol. 16, p. R17, 2003.

[23] S. Soltanian, X. L. Wang, J. Horvat, S. X. Dou, M. D. Sumption, M. Bhatia, E. W. Collings, P. Munroe, and M. Tomsic, "High transport critical current density and large $\mathrm{H}_{\mathrm{c} 2}$ and $\mathrm{H}_{\mathrm{irr}}$ in nanoscale $\mathrm{SiC}$ doped $\mathrm{MgB}_{2}$ wires sintered at low temperature," Supercond. Sci. Technol., vol. 18, p. 658, May 2005.

[24] J. Takada, S. Yamamoto, S. Kikuchi, and M. Adachi, "Determination of diffusion-coefficient of oxygen in gamma-iron from measurements of internal oxidation in Fe-Al alloys," Metall. Mater. Trans. A Phys. Metal. Meter. Sci, vol. 17, p. 221, 1986.

[25] Y. Eltsev, S. Lee, K. Nakao, N. Chikumoto, S. Tajima, N. Koshizuka, and M. Murakami, "Anisotropic superconducting properties of $\mathrm{MgB}_{2}$ single crystals probed by in-plane electrical transport measurements,", Phys. Rev. B, vol. 65, p. 140501, Mar. 2002.

[26] P. C. Canfield, D. K. Finnemore, S. L. Bud'ko, J. E. Ostenson, G. Lapertot, C. E. Cunningham, and C. Petrovic, "Superconductivity in dense $\mathrm{MgB}_{2}$ wires," Phys. Rev. Lett., vol. 86, p. 2423, Mar. 2001.

[27] J. Jiang, B. J. Senkowicz, D. C. Larbalestier, and E. E. Hellstrom, "Influence of boron powder purification on the connectivity of bulk $\mathrm{MgB}_{2}$," Supercond. Sci. Technol., vol. 19, p. L33, July 2006.

[28] D. Dew-Hughes, "Flux pinning mechanisms in type II superconductors," Philos. Mag., vol. 30, p. 293, 1974.

[29] M. Eisterer, "Magnetic properties and critical currents of $\mathrm{MgB}_{2}$," $\mathrm{Su}$ percond. Sci. Technol., vol. 20, p. R47, Oct. 2007. 